\title{
The Dry Etching of TiN Thin Films Using Inductively Coupled $\mathrm{CF}_{4} /$ Ar Plasma
}

\author{
Jong-Chang Woo and Chang-Auck Choi \\ Nano Convergence Sensor Research Section, Electronics and Telecommunications Research Institute, Daejeon 305-700, Korea \\ Young-Hee Joo, Han-Soo Kim, and Chang-II Kim ${ }^{\dagger}$ \\ School of Electrical and Electronics Engineering, Chung-Ang University, Seoul 156-756, Korea
}

Received December 24, 2012; Revised January 23, 2013; Accepted January 23, 2013

\begin{abstract}
In this study, we changed the input parameters (gas mixing ratio, RF power, DC bias voltage, and process pressure), and then monitored the effect on TiN etch rate and selectivity with $\mathrm{SiO}_{2}$. When the RF power, DC-bias voltage, and process pressure were fixed at $700 \mathrm{~W},-150 \mathrm{~V}$, and $15 \mathrm{mTorr}$, the etch rate of TiN increased with increasing $\mathrm{CF}_{4}$ content from 0 to $20 \%$ in $\mathrm{CF}_{4} / \mathrm{Ar}$ plasma. The TiN etch rate reached maximum at $20 \% \mathrm{CF}_{4}$ addition. As RF power, DC bias voltage, and process pressure increased, all ranges of etch rates for TiN thin films showed increasing trends. The analysis of x-ray photoelectron spectroscopy (XPS) was carried out to investigate the chemical reactions between the surfaces of TiN and etch species. Based on experimental data, ion-assisted chemical etching was proposed as the main etch mechanism for TiN thin films in $\mathrm{CF}_{4} / \mathrm{Ar}$ plasma.
\end{abstract}

Keywords: Etching, TiN, XPS, ICP, $\mathrm{CF}_{4}$

\section{INTRODUCTION}

Titanium nitride (TiN) has good diffusion prohibition, low electrical resistance, good thermal and chemical stability, and good adhesive property [1-4]. In addition, TiN has been considered as the most promised candidate to substitute for poly $\mathrm{Si}$ gate electrode, because poly Si gate electrode for the ultra thin gate $\mathrm{SiO}_{2}$ shows some problems of poly depletion through gate oxide and high resistivity $[5,6]$. For TiN gate electrode, it is possible to create fine patterns using high density plasmas, such as inductively coupled plasma (ICP), electron cyclotron resonance plasma (ECR), and helicon wave plasma. Until now, there have been a lot of papers on the etching of TiN thin film using halogen chemistries, such as $\mathrm{Cl}_{2} / \mathrm{Ar}, \mathrm{Cl}_{2} / \mathrm{N} 2, \mathrm{Cl}_{2} / \mathrm{HBr}, \mathrm{Cl}_{2} / \mathrm{Ar} / \mathrm{CHF}_{3}, \mathrm{CHF}_{3} /$ $\mathrm{Ar}, \mathrm{SF}_{6} / \mathrm{Ar}$, and $\mathrm{CF}_{4} / \mathrm{O}_{2}$ [7-10]. But, reports on the etch mecha-

${ }^{\dagger}$ Author to whom all correspondence should be addressed: E-mail: cikim@cau.ac.kr

Copyright @2013 KIEEME. All rights reserved. This is an open-access article distributed under the terms of the Creative Commons Atribution Non-Commercial
License (http://creativecommons.org/licenses/by-nc/3.0) which permits unrestricted noncommercial use, License (http://creativecommons.org/licensesslby-nc/3.0) which permits unrestricted
distribution, and reproduction in any medium, provided the original work is properly cited nism of TiN thin film conflict with one another. Shamiryan et al. reported that the etch rate of TiN was high, due to easy formation of high volatile etch byproducts [7-9] on the other hand, Abraham et al. reported that the etch rate of TiN was slow, and it was difficult to obtain anisotropic etch profiles [10]. The etch process should satisfy the requirements of high etch rate, and selectivity to mask and under-layers of gate oxide or high- $k$ dielectrics, etch profile, and no plasma damage.

In this work, we investigated etching characteristics of TiN to $\mathrm{SiO}_{2}$, using an inductively coupled plasma (ICP) system. Etching characteristics were investigated in terms of TiN thin film, and selectivity of TiN thin film over $\mathrm{SiO}_{2}$ as a function of the etch chemistry. The chemical states on the etched surface were investigated with X-ray photoelectron spectroscopy (XPS).

\section{EXPERIMENTAL DETAILS}

TiN thin films were deposited by atomic layer chemical vapor deposition. The total thicknesses of the TiN thin films were about $100 \mathrm{~nm}$. The dry etching process was performed in an ICP 
system [13], consisting of a cylindrical chamber with a diameter of $26 \mathrm{~cm}$. The top copper coil was operated with $13.56 \mathrm{MHz} \mathrm{RF}$ power, and was located on the chamber lid to generate highdensity plasma. The bottom electrode was connected to another 13.56 MHz asymmetric RF generator, to control the DC-bias voltage. The distance between a quartz window and substrate electrode was $9 \mathrm{~cm}$. The chamber was evacuated to $10^{-6}$ Torr using a mechanical pump (2M80, BOC Edwards), and a turbo molecular pump. The TiN thin films were etched with $\mathrm{CF}_{4} / \mathrm{Ar}$ gas mixing. The gas mixing ratio and process pressure were varied, to find the characteristics of etching. For these experiments, RF power, DC-bias voltage, process pressure and substrate temperature were $700 \mathrm{~W},-150 \mathrm{~V}, 15 \mathrm{mTorr}$ and $45^{\circ} \mathrm{C}$, respectively. In addition, plasma etching of TiN thin films was investigated by including the RF power, DC-bias voltage, and process pressure of $500 \mathrm{~W}$ $650 \mathrm{~W},-150 \mathrm{~V} \sim-300 \mathrm{~V}$, and $9 \sim 20$ mTorr in the $\mathrm{CF}_{4} /$ Ar gas mixing ratio, respectively. The etch rates were measured using a depth profiler (KLA Tencor, $\alpha$-step 500; Sanjoe, Ca, USA). The chemical reactions on the surfaces of the etched TiN thin films were evaluated using X-ray Photoelectron Spectroscopy (XPS, Thermo VG, SIGMA PROBE; East Grinstead, West Sussex, England). The source type for the XPS analysis was $\mathrm{Al} \mathrm{K \alpha}$ with a spot size of 400 $\mu \mathrm{m}$. The energy step size was $0.1 \mathrm{eV}$.

\section{RESULTS AND DISCUSSION}

For the characterization of TiN thin film in a ICP etching system, the plasma etching of TiN thin film and selectivity of TiN to $\mathrm{SiO}_{2}$ were systematically investigated as various etch chemistries. Figure 1 shows the etch rate of TiN thin film, and selectivity of TiN to $\mathrm{SiO}_{2}$ as a function of reactive species concentration, when the total flow rate was maintained at $20 \mathrm{sccm}$. Other process conditions, such as RF power, DC-bias voltage, process pressure, and substrate temperature, were maintained at $700 \mathrm{~W},-150 \mathrm{~V}, 15$ mTorr, and $45^{\circ} \mathrm{C}$, respectively. Comparisons of etch rates of the TiN thin film in Ar- $(72.5 \mathrm{~nm} / \mathrm{min})$ and $\mathrm{CF}_{4^{-}}(72.7 \mathrm{~nm} / \mathrm{min})$ based plasmas showed that the chemical etching was more effective than the physical sputtering. The etch rate of TiN thin film increased, while the selectivity of $\mathrm{TiN}$ to $\mathrm{SiO}_{2}$ paralleled. The result was a lowering of the rate of the chemical reaction in the $\mathrm{CF}_{4}$ plasma, due to the deposition of solid inorganic compounds that resulted from a complete dissociation of the $\mathrm{CF}_{4}$ molecules. The maximum etch rate of TiN was $96.7 \mathrm{~nm} / \mathrm{min}$ at a $20 \%$ of $^{C_{4}} /$ $\left(\mathrm{CF}_{4}+\mathrm{Ar}\right)$ gas mixing ratio. It was well known that fluorine components of TiN thin film form high-volatile by-product, such as $\mathrm{TiF}_{4}$ (melting point: $284^{\circ} \mathrm{C}$ ). The evident enhancement of the TiN thin film etch rate in the pure $\mathrm{CF}_{4}$ plasmas allows one to assume that the chemical etch pathway provided by the $\mathrm{F}$ atom is the dominant mechanism for the given set of process parameters. In the case of the chemical etching of the TiN thin films, we expect the contribution of this pathway to be much lower, compared with the chemical reaction. $\mathrm{In}_{\mathrm{CF}_{4}}$-based plasma, addition of the $\mathrm{CF}_{4}$ up to $20 \%$ increased the etch rate, through the action of two mechanisms: 1) the accelerated chemical reaction by the ionstimulated desorption of the reaction products, and 2) increasing of the contribution of the chemical etching. Nevertheless, when the $\mathrm{CF}_{4}$ content exceeds $20 \%$, the etch rate begins to fall, down due to the "disappearance" of the chemical etching [11,12].

Figure 2 shows the etch rate of TiN thin film as a function of RF power. Other process conditions, such as $\mathrm{CF}_{4} / \mathrm{Ar}(20: 80 \%)$ plasma, DC-bias voltage, and process pressure, were also maintained at - $150 \mathrm{~V}$, and 15 mTorr, respectively. As the RF power increases, the TiN thin film also increases, starting from $75.7 \mathrm{~nm} /$ $\mathrm{min}$ at $500 \mathrm{~W}$, and then reaches a maximum of $125.7 \mathrm{~nm} / \mathrm{min}$ at $900 \mathrm{~W}$. It can be seen that an increase in the RF power causes a

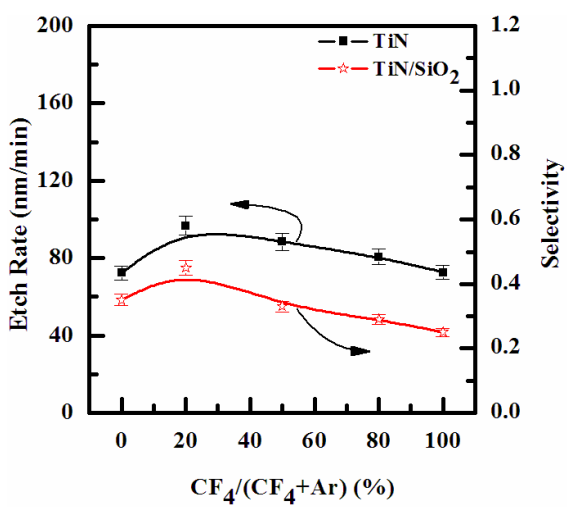

Fig. 1. Etch rates of TiN thin films as a function of the $\mathrm{CF}_{4} / \mathrm{Ar}$ gas mixing ratio. The RF power was maintained at $700 \mathrm{~W}$, the DC-bias voltage was $-150 \mathrm{~V}$, the process pressure was $15 \mathrm{mTorr}$, and the substrate temperature was $45^{\circ} \mathrm{C}$.

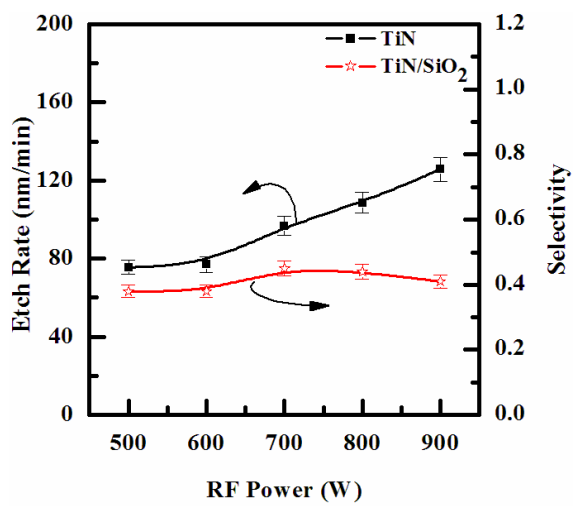

Fig. 2. Etch rates of TiN thin films as a function of the RF power. The gas mixing was maintained at $\mathrm{CF}_{4} / \operatorname{Ar}(20: 80 \%)$ plasma, the DC-bias voltage was maintained at - $150 \mathrm{~V}$, the process pressure was $15 \mathrm{mTorr}$, and the substrate temperature was $45^{\circ} \mathrm{C}$.

monotonic increase in both dissociation and ionization rates, and thus in densities and fluxes of $\mathrm{F}$ atoms and positive ions. In our case, such layer can result from the deposition of solid F that is then bonded with surface oxygen to form Ti-F, as well as from $F$ radicals incorporated in the polymer-like structure.

The etch rates of TiN thin film are shown in Fig. 3 as functions of DC-bias voltage. Other process conditions, such as $\mathrm{CF}_{4} / \mathrm{Ar}(20: 80 \%)$ plasma, RF power and process pressure, were also maintained at $700 \mathrm{~W}$, and 15 mTorr. As the DC-bias voltage increased from - 50 to $-250 \mathrm{~V}$, the etch rate of TiN thin film increased from 51.5 to $184.5 \mathrm{~nm} / \mathrm{min}$. The selectivity of TiN to $\mathrm{SiO}_{2}$ slightly increased. An increase in etch rate can be related to the increase of mean ion energy, resulting in increasing sputtering yields for the TiN thin film and reaction products.

The effect of process pressure on etch rate is shown in Fig. 4. As process pressures increased from 9 to 21 mTorr, the etch rates of TiN decreased from 103.8 to $87.4 \mathrm{~nm} / \mathrm{min}$. However, we obtain a similar non-monotonic behavior, as was mentioned for the effect of the gas mixing ratio. In our opinion, the effect of gas pressure can be explained as follows: an increase in gas pressure at fixed $\mathrm{CF}_{4} / \mathrm{Ar}$ mixing ratio leads to an increase in both density and flux of fluorine atoms on the etched surface, but causes a decrease in ion flux and mean ion energy [13,14]. As a result, with increasing gas pressure, we have a tendency to accelerate in the chemical etch pathway, but a worse condition for the ion 


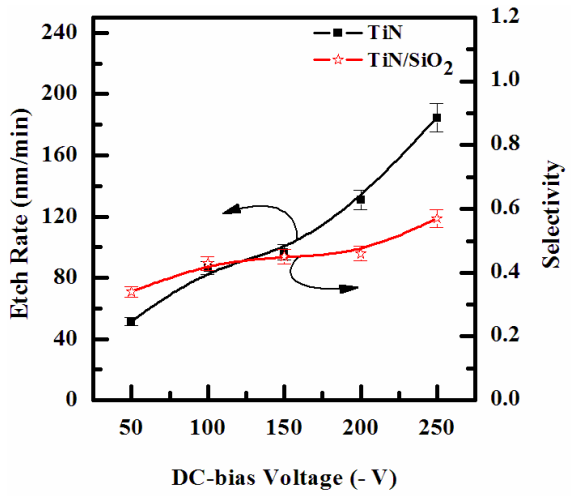

Fig. 3. Etch rates of TiN thin films as a function of the DC-bias voltage. The gas mixing was maintained at $\mathrm{CF}_{4} / \mathrm{Ar}(20: 80 \%)$ plasma, the $\mathrm{RF}$ power was maintained at $700 \mathrm{~W}$, the process pressure was 15 mTorr, and the substrate temperature was $45^{\circ} \mathrm{C}$.

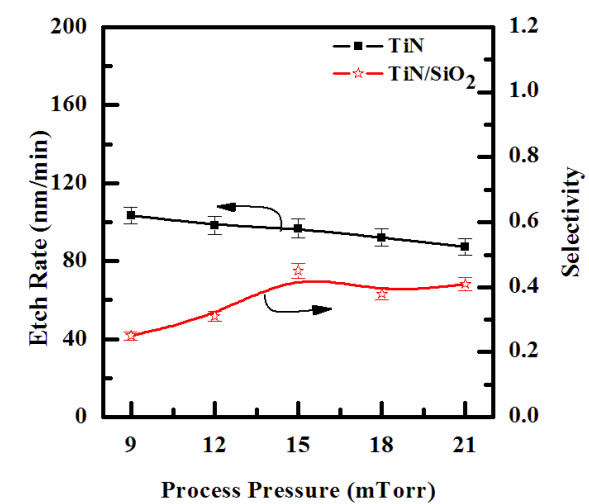

Fig. 4. Etch rates of TiN thin films as a function of the process pressure. The gas mixing was maintained at $\mathrm{CF}_{4} / \mathrm{Ar}(20: 80 \%)$ plasma, the RF power was maintained at $700 \mathrm{~W}$, the DC-bias voltage was - $150 \mathrm{~V}$, and the substrate temperature was $45^{\circ} \mathrm{C}$.

stimulated desorption of reactive products obtains, resulting, probably, in a decreasing fraction of acceptable free surface for chemical reaction. Similar to the effect of the gas mixing ratio discussed above, these two factors, working in opposite directions, produce a non-monotonic behavior of the etch rate.

For more detailed investigations of the chemical reaction between TiN and fluorine atoms, XPS analysis was performed. In order to determine this in detail, XPS narrow scan analysis was performed as a function of $\mathrm{CF}_{4}$ content in $\mathrm{CF}_{4} / \mathrm{Ar}$ plasma. Figure 5 shows narrow scan spectra for Ti $2 p$ from TiN surfaces. As shown in Fig. 5 (a), the $\mathrm{Ti} 2 \mathrm{p}$ corresponded to $\mathrm{TiO}_{\mathrm{x}}(458.65$ $\mathrm{eV}$ ), $\mathrm{Ti}_{\mathrm{x}} \mathrm{O}_{\mathrm{y}}(456.5 \mathrm{eV})$, and $\mathrm{Ti}-\mathrm{N}(455.25 \mathrm{eV})$ bonds, and after the TiN was exposed in $\mathrm{CF}_{4} / \mathrm{Ar}(=20: 80 \%)$ plasma, three peaks corresponded to $\mathrm{TiO}_{\mathrm{x}}$ bond $(457.45 \mathrm{eV}), \mathrm{Ti}_{\mathrm{x}} \mathrm{O}_{\mathrm{y}}$ bond $(455.3 \mathrm{eV})$ and Ti-N bond $(454.05 \mathrm{eV})$. The bonds from TiN thin film may exist at a lower binding energy of $1.2 \mathrm{eV}$. As shown in Fig. 5(c), the $\mathrm{TiO}_{\mathrm{x}}$, $\mathrm{Ti}_{\mathrm{x}} \mathrm{O}_{y}$, and TiN bonds existed at the higher binding energy of 0.3 $\mathrm{eV}$. This indicates that the TiN surface was changed by ion sputtering and the formation of etching byproducts.

Figure 6 shows narrow scan spectra for $\mathrm{N} 1 \mathrm{~s}$ from TiN surfaces. In Fig. 6(a), the peak is observed at $396.8 \mathrm{eV}$. The N 1s peak corresponded to the peak at $397.05 \mathrm{eV}$, and $395.95 \mathrm{eV}$ corresponded to the N-Ti bond or N-Si bond. As shown in Fig. 6(b), the N 1s peak decreases and $\mathrm{N}-\mathrm{Ti}$ and $\mathrm{N}-\mathrm{Si}$ peak increases and a new peak appeared for the N-F bond (401.7 eV). Also, the N-Ti and N-Si bond
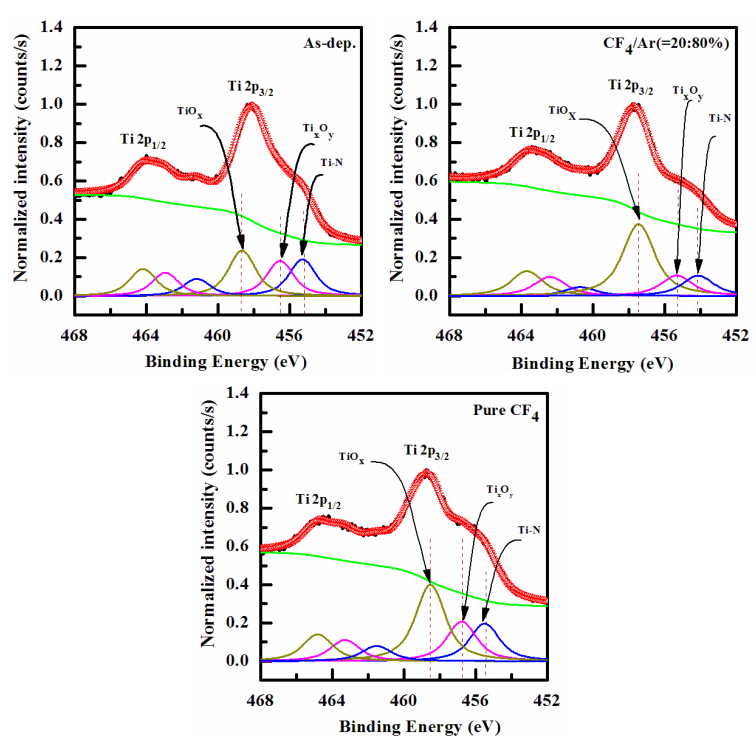

Fig. 5. Ti 2p XPS narrow scan spectra of the etched TiN thin film surface. The RF power was maintained at $700 \mathrm{~W}$, the DC-bias voltage was - $150 \mathrm{~V}$, the process pressure was $15 \mathrm{mTorr}$, and the substrate temperature was $45^{\circ} \mathrm{C}$. (a) As-dep., (b) $\mathrm{CF}_{4} / \mathrm{Ar}=20: 80 \%$, and (c) Pure $\mathrm{CF}_{4}$.
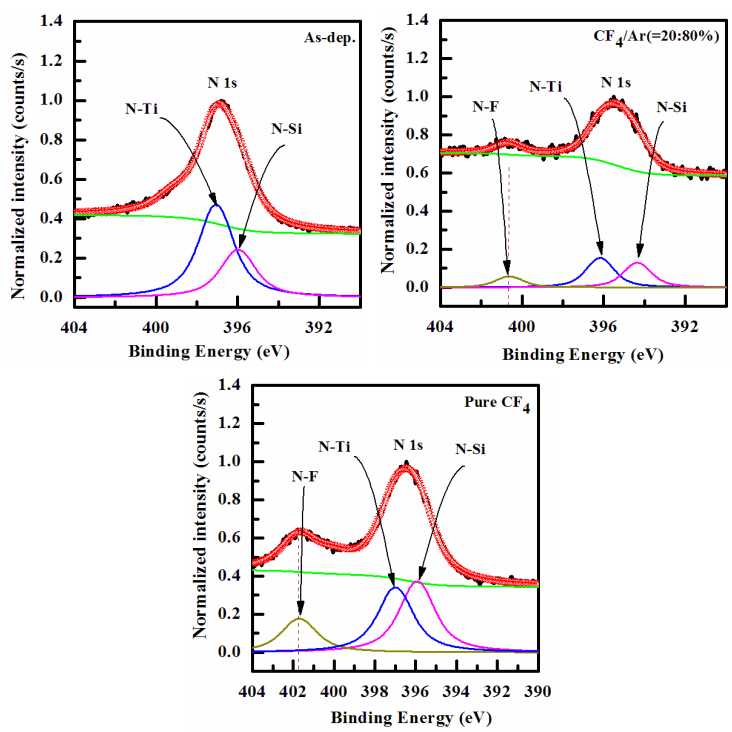

Fig. 6. N 1s XPS narrow scan spectra of the etched TiN thin film surface. The RF power was maintained at $700 \mathrm{~W}$, the DC-bias voltage was - $150 \mathrm{~V}$, the process pressure was $15 \mathrm{mTorr}$, and the substrate temperature was $45^{\circ} \mathrm{C}$. (a) As-dep., (b) $\mathrm{CF}_{4} / \mathrm{Ar}=20: 80 \%$, and (c) Pure $\mathrm{CF}_{4}$.

from $\mathrm{N}$ 1s may exist at a lower binding energy of 0.85 and $1.6 \mathrm{eV}$ at 397.05 and 395.95 eV. In Fig. 6(c), the N-Ti and N-Si peak also decreased after etching in pure $\mathrm{CF}_{4}$ plasma, compared with Fig. 6(a). This indicated that $\mathrm{N}$ can be effectively removed by forming etch byproducts, such as N-Ti bond.

XPS analysis confirmed this. The etch rate behavior of TiN in $\mathrm{CF}_{4} / \mathrm{Ar}(20: 80 \%)$ can be explained as follows; 1$) \mathrm{N}$ can be effectively removed by formation of volatile etch byproduct N-F. 2) The byproduct can accumulate on the TiN surface. The byproduct prevents further chemical reaction between the CF or F radical and the TiN layer. 3) The byproduct can be removed by Ar ion sputtering. The low etch rate in pure $\mathrm{CF}_{4}$ plasma is related to the formation of byproduct. This assumption is in good agreement 


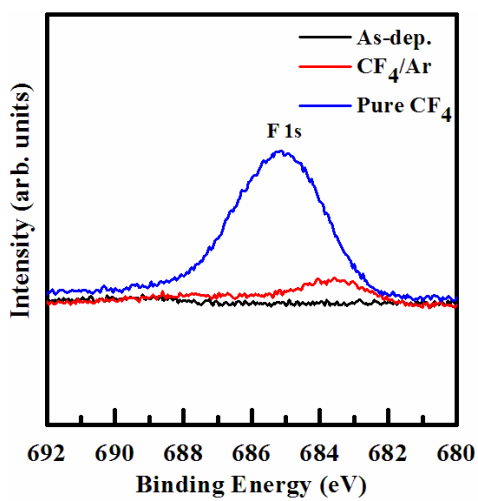

Fig. 7. F 1s XPS narrow scan spectra of the etched TiN thin film surface. The RF power was maintained at $700 \mathrm{~W}$, the DC-bias voltage was - $150 \mathrm{~V}$, the process pressure was $15 \mathrm{mTorr}$, and the substrate temperature was $45^{\circ} \mathrm{C}$.

with the etch rate behavior of TiN, as discussed in Figs. 2-5. The F 1s peaks are shown in the spectrum of Fig. 7, which was obtained from the etched sample. The photoelectron binding energy of $685.2 \mathrm{eV}$ was assigned to $\mathrm{F} 1 \mathrm{~s}$, resulting from the less volatile $\mathrm{TiF}_{\mathrm{x}}$, leading to an increased etch rate with increasing amount of $\mathrm{CF}_{4}$. When the TiN thin films were etched in the $\mathrm{CF}_{4} / \mathrm{Ar}(20: 80 \%)$ and pure $\mathrm{CF}_{4}$ plasmas, the $\mathrm{F} 1 \mathrm{~s}$ peak intensity decreased, owing to the $\mathrm{F}$ atoms from $\mathrm{CF}_{4}$ gas [15-17].

\section{CONCLUSIONS}

Etching characteristics of TiN thin films were investigated in terms of etch rate and selectivity, using $\mathrm{CF}_{4} / \mathrm{Ar}$ plasma. Experiments were performed with variations of $\mathrm{CF}_{4} / \mathrm{Ar}$ gas mixing ratio, $\mathrm{RF}$ power, DC-bias voltage, and process pressure. It was found that addition of $\mathrm{CF}_{4}$ contents up to $20 \%$ led to the etch rate of TiN decreasing, in comparison with at $\mathrm{CF}_{4}$ only. The maximum etch rate of TiN films was $96.7 \mathrm{~nm} / \mathrm{min}$ under $20 \% \mathrm{CF}_{4} /\left(\mathrm{CF}_{4}+\mathrm{Ar}\right)$ in $700 \mathrm{~W},-150 \mathrm{~V}, 15 \mathrm{mTorr}$, and $45^{\circ} \mathrm{C}$. This showed that the increase of $\mathrm{CF}_{4}$ addition enhanced ion bombardment, and made the etch rate decrease. The chemical states of etched TiN films were investigated using XPS, and the chemical reaction between TiN and F was observed. The etching mechanism of TiN thin films can be explained as follows: Ti interacted with the F radical by adding $\mathrm{CF}_{4}$, but non-volatilie etch byproducts such as $\mathrm{TiF}_{\mathrm{x}}$ remained at the surface.

\section{ACKNOWLEDGMENT}

This research was conducted under the industrial infrastructure program for fundamental technologies(N0000417) which is funded by the Ministry of Knowledge Economy(MKE, Korea). [ The Construction of Foundry Base Technology for The Smart Micro-Sensor Commercialization (N0000417)].

\section{REFERENCES}

[1] K. C. Park, K.B. Kim, I. J. M. M. Raaijmakers, K. Ngan; J. Appl. Phys. 80 (1996) 5674 [DOI: http://dx.doi.org/10.1063/1.363620].

[2] R. Hegde, R. Flodalice, E. Travis, P. Tobin; J. Vac. Sci. Technol. B 11 (1993) 1287 [DOI: http://dx.doi.org/10.1116/1.586931].

[3] G. Druais, G. Dilliway, P. Fischer, E. Guidotti, O. Lühn, A. Radisic, S. Zahraoui; Microelectron. Eng. 85 (2008) 1957 [DOI: http:// dx.doi.org/10.1016/j.mee.2008.06.004].

[4] L. Tsetseris, S. Logothetidis, S.T. Pantelides; Appl. Phys. Lett. 94 (2009) 161903 [DOI: http://dx.doi.org/10.1063/1.3122344].

[5] M. Kadoshima, T. Matsuki, S. Miyazaki, K. Shiraishi, T. Chikyo, K. Yamada, T. Aoyama, Y. Nara, Y. Ohji; Electr. Dev. Lett. 30 (2009) [DOI: http://dx.doi.org/466. 10.1109/LED.2009.2016585].

[6] J. K. Schaeffer, D. C. Gilmer, C. Capasso, S. Kalpat, B. Taylor, M. V. Raymond, D. Triyoso, R. Hegde, S. B. Samavedam, B. E. White; Microelectron. Eng. 84 (2007) 2196 [DOI: http://dx.doi. org/10.1016/j.mee.2007.04.130].

[7] H. K. Chiu, T. L. Lin, Y. Hu, K. C. Leou, H. C. Lin, M. S. Tsai, T. Y. Huang; J. Vac. Sci. Technol. A 19 (2001) 455 [DOI: http://dx.doi. org/10.1116/1.1342866].

[8] J. Tonotani, T. Iwamoto, F. Sato, K. Hattori, S. Ohmi, H. Iwai; J. Vac. Sci. Technol. B 21 (2003) 2163 [DOI: http://dx.doi. org/10.1116/1.1612517].

[9] D. Shamiryan, V. Paraschiv, S. Eslava-Fernedez, M. Demand, M. Baklanov, S. Beckx, W. Boullart; J. Vac. Sci. Technol. B 25 (2007) 739 [DOI: http://dx.doi.org/10.1116/1.2731333].

[10] W. S. Hwang, J. Chen, W.J. Yoo; J. Vac. Sci. Technol. A 23 (2005) 964 [DOI: http://dx.doi.org/10.1116/1.1927536].

[11] K. T. Kim, C.I. Kim; Thin Solid Films 472 (2005) 26 [DOI: http:// dx.doi.org/10.1016/j.tsf.2004.05.128].

[12] A. M. Efremov, S. M. Koo, D. P. Kim, K. T. Kim, C. I. Kim; J. Vac. Sci. Technol. A 22, 2101 (2004) [DOI: http://dx.doi. org/10.1116/1.1772370].

[13] G. H. Kim, C.I. Kim, A.M. Efremov; Vacuum 79 (2005) 231 [DOI: http://dx.doi.org/10.1016/j.vacuum.2005.03.012].

[14] A. M. Efremov, D. P. Kim, C. I. Kim; Vacuum 75 (2004) 133 [DOI: http://dx.doi.org/10.1016/j.vacuum.2004.01.077].

[15] R. d'Agostino, F. Fracassi, C. Pacifico; J. Appl. Phys. 72 (1992) 4351 [DOI: http://dx.doi.org/10.1063/1.352199].

[16] T. Matsuki, T. Watanabe, T. Miura, N. Mise, T. Eimori, Y. Nara, Y. Ohji, A. Uedono, K. Yamada; Jpn. J. Appl. Phys. 46 (2007) L1219 [DOI: http://dx.doi.org/10.1143/JJAP.42.L1219].

[17] G. Prumper, X. J. Liu, K. Ueda, Y. Tamenori; Radiation Physics and Chemistry 75 (2006) 2019 [DOI: http://dx.doi.org/10.1016/ j.radphyschem.2005.11.020]. 